\title{
Hepatic lipase gene expression is transiently induced by gonadotropic hormones in rat ovaries
}

\author{
D. Vieira-van Bruggen, ${ }^{\mathrm{a}, \mathrm{b}}$, A.J.M. Verhoeven ${ }^{\mathrm{a}}$, M. Heuveling, ${ }^{\mathrm{a}}$, C. Kalkman ${ }^{\mathrm{a}}$, W.J. de Greef ${ }^{\mathrm{c}}$, \\ H. Jansen ${ }^{\mathrm{a}, \mathrm{b}, *}$ \\ ${ }^{a}$ Department of Biochemistry, Faculty of Medicine and Health Sciences, Erasmus University Rotterdam, P.O. Box 1738, \\ 3000 DR Rotterdam, Netherlands \\ ${ }^{\mathrm{b}}$ Department of Internal Medicine III, Faculty of Medicine and Health Sciences, Erasmus University Rotterdam, \\ 3000 DR Rotterdam, Netherlands \\ ${ }^{\mathrm{c}}$ Department of Endocrinology and Reproduction, Faculty of Medicine and Health Sciences, Erasmus University Rotterdam, \\ 3000 DR Rotterdam, Netherlands
}

Received 14 June 1996; accepted 18 October 1996

\begin{abstract}
Hepatic lipase (HL) gene expression was studied in rat ovaries. A transcript lacking exons 1 and 2 could be detected by reverse transcription-polymerase chain reaction (RT-PCR) in the ovaries of mature cyclic females and of immature rats treated with pregnant mare serum followed by human chorionic gonadotropin (hCG) to induce superovulation. By competitive RT-PCR the HL transcript was quantified. Low levels of HL mRNA were detected in ovaries of mature cyclic females and of immature rats. During superovulation HL mRNA was several fold higher than in mature cyclic rats and transiently increased to a maximum at 2 days after hCG treatment. Pulse-labelling of ovarian cells and ovarian slices with ${ }^{35}$ S $]$ methionine followed by immunoprecipitation with polyclonal anti-HL IgGs showed de novo synthesis of a $47 \mathrm{kDa}$ HL-related protein. Expression of the protein was transiently induced by gonadotropins with a peak at 2 days after hCG treatment. Induction of liver-type lipase activity occurred only after HL mRNA and synthesis of the HL-related protein had returned to pre-stimulatory levels. We conclude that in rat ovaries the HL gene is expressed into a variant mRNA and a $47 \mathrm{kDa}$ protein. The expression of the HL gene in ovaries is inducible and precedes the expression of the mature, enzymatically active liver-type lipase. Copyright (C) 1997 Elsevier Science Ireland Ltd.
\end{abstract}

Keywords: Hepatic lipase; Liver-type lipase; Steroidogenesis; Ovary; Superovulation; Polymerase-chain reaction

\section{Introduction}

Ovaries and adrenals of rats and humans have been shown to contain a lipase activity (liver- or l-type lipase) similar to hepatic lipase (HL) normally present in liver sinusoids [1-5]. Whereas the liver enzyme plays a role in the uptake of circulating lipoproteins and its components, the $l$-type lipase in the steroidogenic organs is suggested to mediate the delivery of high-density lipoprotein cholesterol required for hormone synthesis

\footnotetext{
* Corresponding author. Tel.: + 3110 4087325; fax: + 3110 4360615; e-mail: Jansen@bc1.fgg.eur.nl
}

[6]. In rat ovaries, the $l$-type lipase activity is mainly localized in the corpora lutea, which are most active in steroidogenesis [4,7] and is increased several-fold in immature rats upon induction of superovulation [8]. The l-type lipase activity in the ovaries varies during the oestrous cycle and lactation in parallel with progesterone and $20 \alpha$-hydroxyprogesterone output $[2,7,8]$.

The $l$-type lipase present in steroidogenic organs is thought to originate from the liver since full-length HL mRNA was not detected in adrenals and ovaries $[9,10]$. In this model, the lipase is secreted by the parenchymal liver cells, and then transported through the circulation 
to the steroidogenic organs. Rat ovaries are indeed shown to selectively sequester $\left[{ }^{125} \mathrm{I}\right] \mathrm{HL}$ from the circulation [9]. We recently found that the HL gene is transcribed in rat ovaries as well as in human and rat adrenals [11]. In rat adrenals, however, the mRNA product markedly differed from that in liver [12]. In the adrenal mRNA, the exons 1 and 2 of the HL gene are replaced by a novel sequence, so that it no longer encodes for the normal HL protein. Instead, a candidate translation product of about $45 \mathrm{kDa}$ was identified [12]. This prompted us to study HL gene expression in rat ovaries. We show here that the HL gene products in the ovaries resemble that found in adrenal glands. Moreover, HL gene expression in ovaries is transiently stimulated several-fold upon induction of superovulation and was found to precede the acquisition of enzymatically active $l$-type lipase.

\section{Materials and methods}

\subsection{Tissues}

Locally bred Wistar rats were housed under controlled conditions of temperature, humidity and light (12 h light/12 h dark; light on at 07:00 a.m.), with free access to tap water and to a standard pellet diet. Animals were killed by decapitation under light diethyl ether narcosis. Ovaries were dissected from mature cyclic rats weighing 250-300 g. Alternatively, ovaries were isolated from 25-30 days old female rats in which superovulation was induced by a s.c. injection of $10 \mathrm{IU}$ pregnant mare serum (PMS) (Gestyl, Organon, Oss, Netherlands) followed 2 days later with an injection of 10 IU human chorionic gonadotropin (hCG; Pregnyl, Organon, Oss, Netherlands). The day of hCG injection was designated as day 0 . The dissected ovaries were placed in ice-cold phosphate-buffered saline (PBS) and the adherent fat tissue was rapidly trimmed off. Liver and whole adrenals were dissected from young adult males weighing 200-250 g. The tissues were either used immediately, or frozen in liquid nitrogen and stored at $-80^{\circ} \mathrm{C}$.

\subsection{RNA analysis}

Total RNA was isolated from whole organs by the method of Chomczynski and Sacchi [13]. RNA concentrations were determined by spectrophotometry at 260 $\mathrm{nm}$ [14]. The quality of the RNA preparations was judged from the pattern of ribosomal RNA after gelelectrophoresis [14]. HL mRNA was determined by a single tube reverse transcription-polymerase chain reaction (RT-PCR) starting from $1 \mu \mathrm{g}$ of total RNA [12]. Random-primed cDNA was amplified for 30-35 cycles using different HL-specific primers. HL-1 (5'-GTG
GGC ATC AAA CAG CCC-3', nt 712-729; numbering according to the rat cDNA sequence [15] and HL-2 (5'-CAG ACA TTG GCC CAC ACT-3', nt 1307-1289) were used in quantitative PCR. The sense oligonucleotides HL-12 (5'-TGG CTT GCT AGA AAC CTG G-3', nt 297-315), HL-13 (5'-TGT CAT GAT CAT CCA CGG G-3', nt 267-285) and INT (5'-GCA TTG TCC TTG AGC CTG AG-3, nt-112 to - 93 according to the sequence upstream of exon 3 in adrenal HL mRNA [12]) were used in combination with the antisense oligonucleotide HL-9 (5'-GGC ATC ATC TGG AGA AAG GC-3', nt 660-641) to determine the 5'-end of the HL mRNA. Quantitation of HL mRNA was done by competitive RT-PCR, in which $1 \mu \mathrm{g}$ tissue RNA was mixed with $0.5 \mu \mathrm{g}$ yeast RNA (Pharmacia, Uppsala, Sweden) containing increasing amounts of competitor RNA prior to reverse transcription and amplification [12]. The competitor RNA was obtained by in vitro transcription of an HL cDNA clone in pBluescript $\mathrm{KS}^{-}$which had been modified by deletion of an internal 80-bp Sau3A fragment (nt 1009-1088, numbering according to [15]). The amount of target RNA was determined from ethidium-bromide-stained gels by taking (or extrapolating to) the amount of internal competitor RNA that produced an equal signal intensity. All RT-PCR experiments included no-template and no-RT controls that remained negative.

\subsection{Pulse-labelling with $\left[{ }^{35}\right.$ S]methionine}

Pulse-labelling studies were performed either with whole-ovary slices, or with ovarian cells isolated from female rats 2 days after treatment with hCG. Freshly dissected ovaries were roughly minced using a razor blade. The resulting slices were incubated in $1 \mathrm{ml}$ methionine-free minimum essential medium, Eagle's modified (MEM) containing $25 \mathrm{U} / \mathrm{ml}$ heparin (Leo Pharmaceuticals, Weesp, Netherlands) and $20 \%$ bovine serum (dialysed and lipoprotein-free) at $37^{\circ} \mathrm{C}$ in a shaking water bath under an atmosphere of $5 \% \mathrm{CO}_{2} / 95 \%$ $\mathrm{O}_{2}$. In some experiments, the tissue slices were first incubated for $45 \mathrm{~min}$ at $37^{\circ} \mathrm{C}$ with $3 \mathrm{mg} / \mathrm{ml}$ of collagenase (type I, Sigma, St. Louis, USA); thereafter, intact cells were collected by centrifugation $(10 \mathrm{~min}, 100 \times g$, $20^{\circ} \mathrm{C}$ ) through a cushion of $0.5 \%$ BSA in PBS [16]. The cell pellet was resuspended in methionine-free MEM and incubated in a final concentration of $1-2 \times 10^{6}$ cells $/ \mathrm{ml}$ as described above for the tissue slices. After 30 min incubation, $80 \mu \mathrm{Ci}$ of $\operatorname{Tran}^{35} \mathrm{~S}$-label (ICN, Cosa Mesa, USA) was added and the pulse-labelling was allowed to proceed for $2 \mathrm{~h}$. The incubation was stopped on ice, and the cells/tissue and cell-free media were separated by centrifugation $\left(10000 \times g, 20 \mathrm{~s}, 4^{\circ} \mathrm{C}\right)$. The cell pellet was washed twice with ice-cold PBS and then lysed for $45 \mathrm{~min}$ at $4^{\circ} \mathrm{C}$ in PBS containing $1 \%$ Triton $\mathrm{X}-100,1 \%$ sodium deoxycholate, $10 \mathrm{mM}$ Hepes $(\mathrm{pH}$ 
7.4), $25 \mathrm{U} / \mathrm{ml}$ heparin, $1 \mathrm{mM}$ L-methionine, $1 \mathrm{mM}$ EDTA, $10 \mu \mathrm{g} / \mathrm{ml}$ benzamidine, $10 \mathrm{U} / \mathrm{ml}$ Trasylol, and 1 $\mu \mathrm{g} / \mathrm{ml}$ each of leupeptin, antipain, chymostatin and pepstatin. After centrifugation $(10 \mathrm{~min}, 10000 \times g$, $4^{\circ} \mathrm{C}$ ), the lysates were used for immunoprecipation.

\subsection{Immunoprecipitation}

Tissue and cell lysates were pre-cleared by incubation for $2 \mathrm{~h}$ at $4^{\circ} \mathrm{C}$ with non-immune goat IgG immobilized onto Sepharose-4B (Pharmacia, Uppsala, Sweden). After removal of the beads, the lysates were incubated overnight with polyclonal goat anti-rat HL IgGs coupled to Sepharose-4B. Some immunoprecipitations were carried out in the presence of an excess unlabelled, partly purified rat hepatic lipase [17]. The beads were collected by centrifugation and then washed with $1 \mathrm{ml}$ of, successively, PBS, $1 \mathrm{M} \mathrm{NaCl}$ in PBS, $0.2 \%$ Tween20 in PBS and PBS (all at $4^{\circ} \mathrm{C}$ ). The final pellet was resuspended in Laemmli sample buffer [18], heated for $5 \mathrm{~min}$ at $95^{\circ} \mathrm{C}$ and the beads were removed by centrifugation. The released proteins were analyzed by SDSPAGE on a $10 \%$ polyacrylamide gel, followed by fluorography using Amplify (Amersham, UK). The autoradiograms were scanned with the HP ScanJet II CX densitometer, and the integrated optical density was expressed in arbitrary units.

\section{5. l-Type lipase assay}

The ovaries were homogenized in $10 \mathrm{Vol}$. of ice-cold PBS (pH 7.4) containing $5 \mathrm{U} / \mathrm{ml}$ of heparin and $1 \mathrm{mM}$ benzamidine. After centrifugation $(10000 \times g, 2 \mathrm{~min}$, $4^{\circ} \mathrm{C}$ ), the post-nuclear supernatant was assayed for triacylglycerol hydrolase activity at $\mathrm{pH} 8.5$ in $0.6 \mathrm{M}$ $\mathrm{NaCl}$ using a gum-acacia stabilized glycerol $\left[{ }^{3} \mathrm{H}\right]$ trioleate emulsion as substrate [3]. In immunoinhibition assays, the supernatant was pre-incubated for $1 \mathrm{~h}$ at $4^{\circ} \mathrm{C}$ with excess goat anti-rat HL IgGs immediately before the lipase assay. HL activity is defined here as the triglyceridase activity that was sensitive to immunoinhibition [17]. Enzyme activities were expressed as $\mathrm{mU}$ (nmol of free fatty acids released per min).

\section{Results}

\subsection{Effect of gonadotropins on $H L m R N A$ in rat ovaries}

RT-PCR on total ovary RNA isolated from mature cyclic rats and from immature superovulating rats using the primers HL-1 and HL-2 yielded the expected 596bp product, whose identity with part of HL cDNA has been confirmed by restriction mapping and internal re-amplification [11]. In order to obtain UV-detectable
DNA bands, 5-10 extra cycles of amplification were required with RNA from mature rats than from that of superovulating animals, suggesting that the amount of HL mRNA was higher in the gonadotropin-stimulated ovaries. Quantitation of HL mRNA was done by competitive RT-PCR using HL RNA that lacked an internal 80-nt fragment as competitor (Fig. 1). In five independent ovaries from cyclic female rats, the amount of HL mRNA ranged from 0.002 to 0.005 attomoles per $\mu \mathrm{g}$ of total RNA. In the ovaries from superovulating rats, the amount of HL mRNA was at least ten-fold higher at $0.05-0.4$ attomoles per $\mu \mathrm{g}$ total RNA, depending on the treatment with gonadotropins (see below). Using the same assay, rat liver was shown to contain 5-10 attomoles HL mRNA per $\mu$ g total RNA. Hence, the HL gene is expressed in rat ovaries to a level two to three orders lower than in liver.

Although part of the HL gene transcript could be detected by RT-PCR in ovaries, we were unable to amplify the entire HL cDNA from ovary RNA, either isolated from mature cyclic rats or from young superovulating rats. For rat adrenals, we recently reported that the HL gene is transcribed into a variant mRNA in which exons 1 and 2 are replaced by a unique sequence [12] representing part of intron 2 immediately upstream of exon 3 (manuscript in preparation). To test whether this also holds for the ovaries, RT- PCR was performed using HL-9, a down-stream primer recognizing exon-5, in combination with different upstream primers (Fig. 2). With HL-12, an exon-3 specific oligonucleotide, the expected 481-bp product was obtained with RNA from
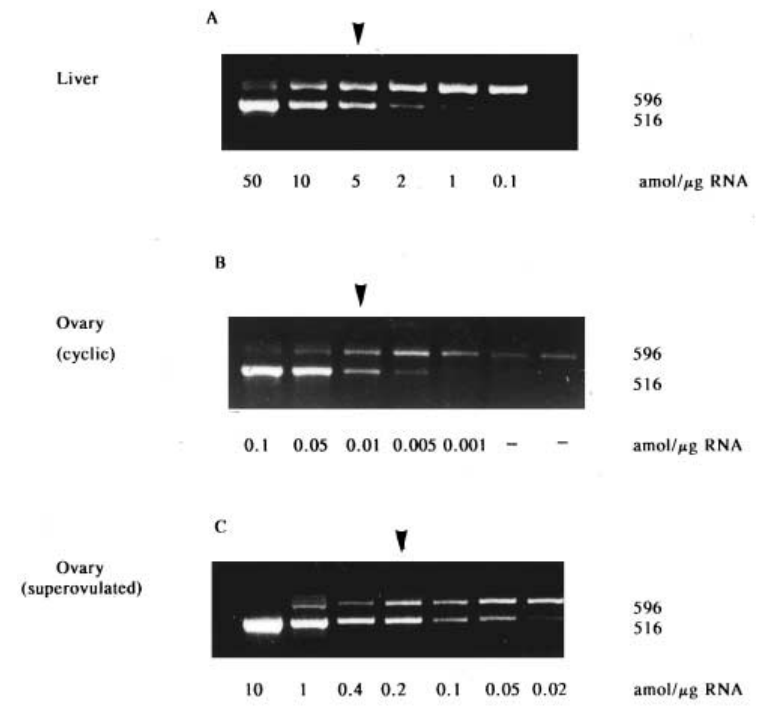

Fig. 1. Quantitation of HL mRNA by competitive RT-PCR. Competitive RT-PCR was performed in total tissue RNA from rat liver (A), ovaries from mature cyclic (B) and from immature superovulated rats 2 days treated with hCG (C). To $1 \mu \mathrm{g}$ RNA the indicated amount of competitor was added. Amplification was performed in 20 (liver), 30 (superovulated rats) or 35 cycles (cyclic rats). The arrowheads indicate the lanes where intensities of both bands are identical. 
A

rat HL CDNA

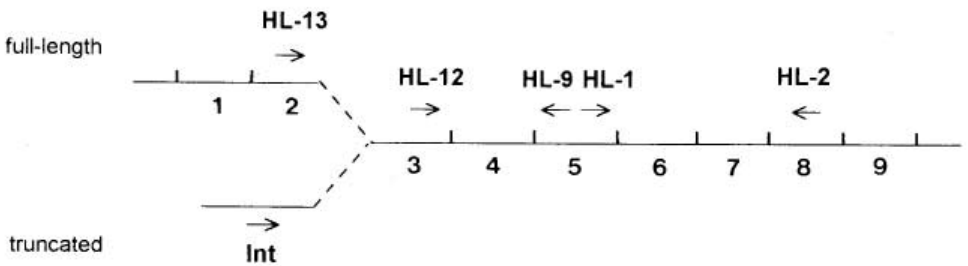

B

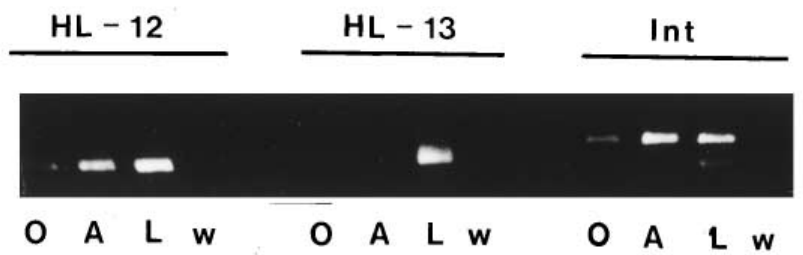

Fig. 2. Detection of the HL mRNA by RT-PCR in liver and steroidogenic tissues. The exon organization of the rat full-length HL cDNA and the alternative $5^{\prime}$-end found in steroidogenic tissues is represented in (A). The arrows show the position and orientation of the oligonucleotides used in RT-PCR. HL mRNA in ovary (O), adrenal (A) and liver (L) was detected by RT-PCR (B). A water control (w) was used. RNA was reverse-transcribed and amplified as described in Materials and methods using the given upstream primer and HL-9 as a common downstream primer. The resulting cDNA was amplified for 30 (liver and adrenal) or 40 (ovary) cycles.

stimulated ovaries as well as with adrenals and liver. With HL-13, an exon-2 specific primer, the expected 511-bp band was observed with liver, but not with ovaries or adrenals. Using INT, which anneals to the unique $5^{\prime}$-end of the variant $\mathrm{HL}$ mRNA transcript found in adrenals and liver [12], a 598-bp product was obtained with ovaries, similar to the expected band seen with adrenals and liver. The 598-bp amplimers from ovaries and adrenals were identical, as determined by direct sequencing (data not shown). We conclude therefore, that in rat ovaries the HL gene is transcribed virtually only into the variant HL message also found in adrenals.

\subsection{De novo synthesis of $H L$-related proteins}

The de novo synthesis and secretion of HL-related proteins was studied in freshly isolated ovarian cells and in ovarian slices, by pulse-labelling with $\left[{ }^{35}\right.$ S $]$ methionine followed by immunoprecipitation with polyclonal anti-HL IgGs. In ovarian cells no radiolabelled protein was detected in the 55-60 kDa range corresponding to mature HL synthesized and secreted by rat liver (Fig. 3). Instead, four major ${ }^{35}$ S-labelled protein bands with apparent $\mathrm{M}_{\mathrm{w}}$ of $200,67,50$ and 47 $\mathrm{kDa}$ were obtained. Even after $2 \mathrm{~h}$ pulse-labelling, these bands were not detectable in the cell-free medium, indicating that these proteins remained intracellularly. These bands co-migrated with the proteins immunoprecipitated from pulse-labelled rat adrenocortical cells (data not shown). In contrast to the 67 and $50 \mathrm{kDa}$ band, immunoprecipitation of the $200 \mathrm{kDa}$ and $47 \mathrm{kDa}$ bands was markedly suppressed by the inclusion of excess cold HL partially purified from rat liver perfusates. Qualitatively similar results were obtained using a mixture of five different monoclonal anti-HL antibodies. In all conditions tested thus far, the ${ }^{35} \mathrm{~S}$-radioactivity of the 200 and $47 \mathrm{kDa}$ bands varied in parallel.

\subsection{Effect of gonadotropins on HL gene expression}

The expression of the variant HL mRNA in rat ovaries was compared with that of the $47 \mathrm{kDa}$ HL-related protein at different times after hCG treatment. As shown in Fig. 4, the amount of the variant HL mRNA was increased approximately four-fold 2 days after treatment with hCG. Six days after treatment with hCG the HL mRNA had decreased again to pre-stimulatory levels. The de novo synthesis of the 200 and $47 \mathrm{kDa}$ proteins was also transiently increased during superovulation (Fig. 4). After 2 days of treatment with hCG 


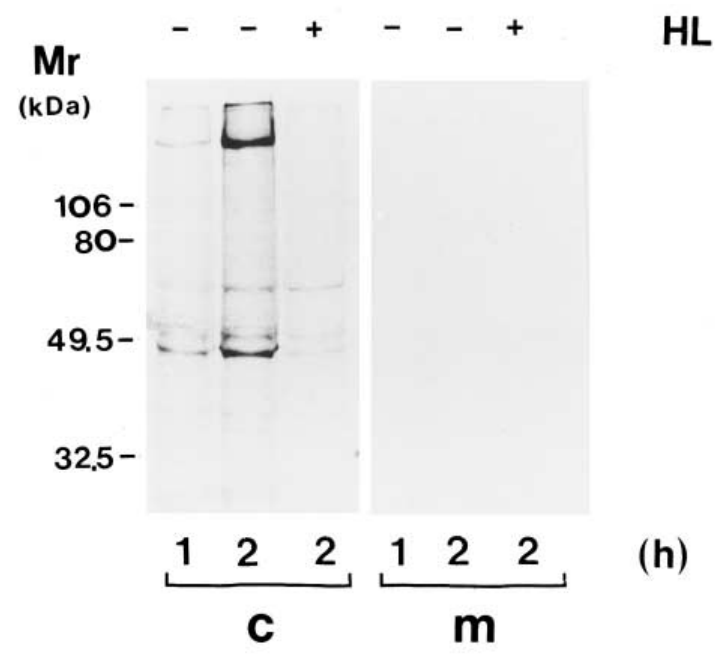

Fig. 3. Pulse-labelling of ovarian cells with $\left[{ }^{35} \mathrm{~S}\right]$ methionine. Freshly isolated ovarian cells from 2 days treated females with hCG were pulse-labelled for 1 or $2 \mathrm{~h}$. Cell lysates (c) and cell-free medium (m) were immunoprecipitated with polyclonal anti-HL IgGs coupled to Sepharose-4B beads in presence $(+)$ and in absence $(-)$ of an excess of unlabelled purified HL. The adsorbed proteins were analyzed by SDS-PAGE on a $10 \%$ gel followed by fluorography. The position of the molecular weight standards is given in $\mathrm{kDa}$.

the ${ }^{35} \mathrm{~S}$-incorporation into both HL-related proteins increased several-fold. Thereafter, the ${ }^{35} \mathrm{~S}$-incorporation decreased again and returned to pre-stimulatory levels 6

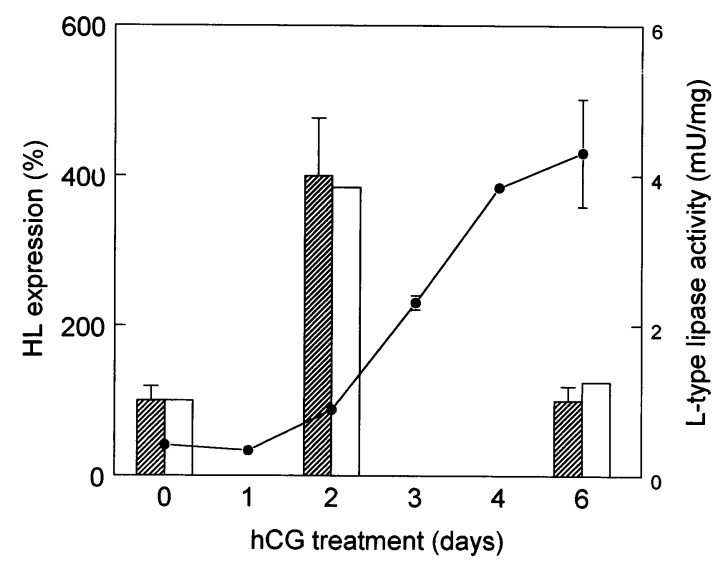

Fig. 4. Transient HL gene expression in immature rat ovaries induced by hCG. Female rats (25-30 days old) were treated with 10 IU PMS followed 2 days later by $10 \mathrm{IU}$ hCG (day 0 ). Of each animal, one ovary was used for RNA measurement, whereas the other ovary was used for protein measurements. Quantitation of HL mRNA (hatched bars) was carried out by RT-PCR using primers HL-1 and HL-2; data are given as $\%$ of results of day $0 ; 0.075 \pm 0.01$ amoles $/ \mu \mathrm{g}$; (mean $\pm \mathrm{SE}, n=3$ ). Ovarian tissue slices were pulse-labelled with $\left[{ }^{35} \mathrm{~S}\right]$ methionine for $2 \mathrm{~h}$ followed by immunoprecipitation and SDSPAGE. The gel was then exposed to a film and the $47 \mathrm{kDa}$ protein band was scanned. Data (open bars) are expressed in arbitrary units of relative blackness given as $\%$ of day 0 , and are representative for 2 independent experiments. l-Type lipase activity $(\bullet)$ was measured in tissue homogenates and given as the lipase activity sensitive to polyclonal anti-HL antibodies (mean $\pm \mathrm{SE}, n=3$ ). days after hCG treatment. Thus, the expression pattern of the variant $\mathrm{HL}$ mRNA and ${ }^{35} \mathrm{~S}$ incorporation into the $47 \mathrm{kDa}$ protein was similar. The effect of $\mathrm{hCG}$ on the $l$-type lipase activity in the stimulated ovaries showed a strikingly different pattern (Fig. 4). The enzyme activity began to increase after 2 days of treatment with hCG and continued to increase thereafter. On a mg protein basis, the $l$-type lipase activity present in the ovaries was maximal after 4 days of hCG treatment and remained high at least until 6 days after hCG injection.

\section{Discussion}

We show here that the rat HL gene is transcribed into a variant mRNA, not only in adrenals, but also in ovaries. This transcript appears to be the major, if not only, HL gene product in these steroidogenic organs. In the liver, it is also present but as a minor component compared to the full-length message encoding HL [12]. As discussed before, this second HL gene product may represent an alternatively spliced form, or may be the product of an alternative transcription start site in the intron preceding exon-3. Since this variant mRNA lacks the first two coding exons of the full-length form found exclusively in liver, its possible translation product would be considerably shorter than the $58 \mathrm{kDa}$ HL protein. Moreover, the protein product would probably remain intracellularly because of the absence of a signal peptide. Whether such a protein product would be catalytically active is presently unknown. It is unlikely, however, that such a protein is responsible for the $l$-type lipase activity found in the steroidogenic organs, since (i) the abundance of HL gene transcripts in adrenals and ovaries is 10 - to 100 -fold less than in liver, despite the presence of a similar lipase activity per mg protein [8] and (ii) the pattern of expression of the $l$-type lipase activity in ovaries during superovulation differs markedly from that of HL mRNA. This study therefore strengthens the hypothesis that the l-type lipase activity found in rat ovaries originates from liver $[9,10]$. Hepatic lipase injected into the circulation is selectively sequestered by the ovaries [9]. During PMS/ hCG-induced neovascularization and differentiation of the ovary the hepatic lipase appeared specifically in the blood vessels of the theca interna of follicles, corpora lutea and interstitial tissue [19]. How the lipase is transported from the liver to the steroidogenic organs and how the protein is specifically sequestered into these organs remains to be determined.

Two immunoreactive proteins of 47 and $200 \mathrm{kDa}$ were found in ovaries as well as in adrenals (data not shown) after pulse-labelling and immunoprecipitation. The $47 \mathrm{kDa}$ protein would be an obvious candidate as a translation product of the variant HL mRNA. This is 
strongly supported by the resemblance in the transient expression pattern of both the HL-related protein and the HL mRNA upon induction of superovulation. Since the unique 5 -end of the variant HL mRNA contains multiple translation stop codons and lacks potential start codons, translation must have started at the first in-frame AUG, which occurs in exon 4 upstream of the catalytic triad [12]. Hence, this protein may possess esterase activity towards some ester substrates. The 200 $\mathrm{kDa}$ band always varied in parallel with the $47 \mathrm{kDa}$ in the immunoprecipitates, suggesting that their expression is somehow related. Whether the high $\mathbf{M}_{\mathrm{w}}$ protein represents aggregates of the $47 \mathrm{kDa}$ form, or a $47 \mathrm{kDa}$ protein covalently linked to another protein, is presently under investigation in our laboratory.

The finding that the HL gene is transcribed into a variant mRNA, and possibly is translated into a $47 \mathrm{kDa}$ HL-related protein, exclusively in the steroid-producing organs, suggests a role for this gene product in cholesterol metabolism. Induction of follicle development and corpora lutea formation by treatment with PMS and hCG, results in a marked increase in steroid hormone production by the ovaries and hence in a demand for cholesterol [7]. Cholesterol needed for steroid production is either mobilized from endogenous cholesterol ester stores, synthesized de novo, or delivered to the ovaries by circulating high- and low-density lipoprotein (HDL and LDL), processes mediated by the $l$-type lipase and the LDL receptor, respectively [20]. The transient expression of the HL gene in ovaries of superovulating rats observed here (Fig. 4) coincides with the fall in intracellular cholesterol esters and parallels the transient increase in cholesterol de novo synthesis [21]. Taken together, these data suggest a role, either structural or catalytical, for the variant HL gene product in the de novo synthesis and/or mobilization of endogenous cholesterol in these organs. At the time that the endogenous cholesterol becomes limited, the extracelluarly localized $l$-type lipase is increased. This enzyme facilitates the influx of HDL-cholesterol in a process possibly involving the recently identified SR-BI receptor [22].

\section{Acknowledgements}

D. Vieira-van Bruggen is a recipient of a JNICTPraxis XXI fellowship, Portugal.

\section{References}

[1] Jansen, H. and De Greef, W.J. (1981) Heparin-releasable lipase activity of rat adrenals, ovaries and testes. Biochem. J. 196, 739-745.

[2] Gåfvels, M., Bengtsson-Olivecrona, G. and Olivecrona, T. (1989) Correlation of plasma progesterone concentration to ovarian H-type lipase activity during pseudopregnancy in the rat. J.
Reprod. Fertil. 86, 589-598.

[3] Jansen, H. and Birkenhäger, J.C. (1981) Liver lipase-like activity in human and hamster adrenocortical tissue. Metabolism 30, $428-430$.

[4] Hixenbaugh, E.A. and Paavola, L.G. (1991) Heterogeneity among ovarian blood vessels: endogenous hepatic lipase is concentrated in blood vessels of rat corpora lutea. Anat. Rec. 230, 291-306.

[5] Persoon, N.L.M., Sips, H.J., Hülsmann, W.C. and Jansen, H. (1986) Monoclonal antibodies against salt-resistant rat liver lipase. Cross-reactivity with lipases from rat adrenals and ovaries. Biochim. Biophys. Acta 875, 286-292.

[6] Jansen, H. and Hülsmann, W.C. (1985) Enzymology and physiological role of hepatic lipase. Biochem. Soc. Trans. 13, 24-26.

[7] Jansen, H., De Greef, W.J. and Uilenbroek, J.Th.J. (1985) Localization of liver-type lipase in rat ovaries and its activity during the estrous cycle and lactation. Mol. Cell. Endocrinol. 42, $253-258$.

[8] Jansen, H. and De Greef, W.J. (1988) L-type lipase activity in ovaries of superovulated rats. Mol. Cell. Endocrinol. 57, 7-15.

[9] Hixenbaugh, E.A., Sullivan, T.R., Strauss III, J.F., Jr., Laposata, E.A., Komaromy, M. and Paavola, L.G. (1989) Hepatic lipase in rat ovary. Ovaries cannot synthesize hepatic lipase but accumulate it from the circulation. J. Biol. Chem. 264, 42224230.

[10] Doolittle, M.H., Wong, H., Davis, R.C. and Schotz, M.C. (1987) Synthesis of hepatic lipase in liver and extrahepatic tissues. J. Lipid Res. 28, 1326-1334.

[11] Verhoeven, A.J.M. and Jansen, H. (1994) Hepatic lipase mRNA is expressed in rat and human steroidogenic organs. Biochim. Biophys. Acta 1121, 121-124.

[12] Verhoeven, A.J.M., Carling, D. and Jansen, H. (1994) Hepatic lipase gene is transcribed in rat adrenals into a truncated mRNA. J. Lipid Res. 35, 966-975.

[13] Chomczynski, P. and Sacchi, N. (1987) Single-step method of RNA isolation by acid guanidinium thiocyanate-phenol-chloroform extraction. Anal. Biochem. 162, 156-159.

[14] Sambrook, J., Fritsch, E.F. and Maniatis, T. (1989) Molecular Cloning, A Laboratory Manual, 2nd edn, Cold-spring Harbor Laboratory Press, New York.

[15] Komaromi, M.C. and Schotz, M.C. (1987) Cloning of rat hepatic lipase cDNA: evidence for a lipase gene family. Proc. Natl. Acad. Sci. USA 84, 1526-1530.

[16] Azhar, S., Chen, Y.-D.I. and Reaven, G.M. (1983) Stimulation of lipoprotein receptors and role of lipoprotein and cellular cholesterol during gonadotropininduced desensitization of steroidogenic response in luteinized rat ovary. J. Biol. Chem. 258 (6), 3735-3740.

[17] Verhoeven, A.J.M. and Jansen, H. (1991) Secretion-coupled increase in the catalytic activity of rat hepatic lipase. Biochim Biophys. Acta 1086, 49-56.

[18] Laemmli, U.K. (1970) Cleavage of structural proteins during the assembly of the head of bacteriophage T4. Nature 227 (259), $680-685$.

[19] Hixenbaugh, E.A., Strauss III, J. F. and Paavola, L.G. (1993) Establishment of heterogeneity among blood vessels: hormoneinfluenced appearance of hepatic lipase in specific subsets of the ovarian microvasculature. Anat. Rec. 235, 487-500.

[20] Brown, M.S., Kovanen, P.T. and Goldstein, J.L. (1979) Receptor-mediated uptake of lipoprotein-cholesterol and its utilization for steroid synthesis in the adrenal cortex. Recent Prog. Horm. Res. 35, 215-157.

[21] Reaven, E., Tsai, L. and Azhar, S. (1995) Cholesterol uptake by the 'selective' pathway of ovarian granulosa cells: early intracellular events. J. Lipid Res. 36 (7), 1602-1617.

[22] Acton, S., Rigotti, A., Landschulz, T., Xu, S., Hobbs, H.H. and Krieger, M. (1996) Identification of scavenger receptor SR-BI as a high density lipoprotein receptor. Science 271, 518-520. 